\begin{tabular}{|c|c|}
\hline & $\begin{array}{l}\text { International Journal of Trend in Scientific } \\
\text { Research and Development (IJTSRD) }\end{array}$ \\
\hline 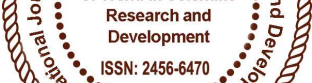 & International Open Access Journal \\
\hline 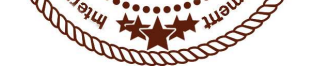 & ISSN No: 2456 - 6470 | www.ijtsrd.com | Volume - 2 | Issue - 2 \\
\hline
\end{tabular}

\title{
Socio-economic Dimensions, Issues and Implications of Post- Independence Odisha and its Manifestation in Odia Poetry with a Special Case Study of Guruprasad Mohanty's Kaalapurusha
}

\author{
Santosh Kumar Nayak \\ Assistant Professor and Head, (O.E.S.-I) \\ Post Graduate Department of Odia Language and Literature \\ Government College, Dayananda Vihar, Koraput, Odisha-764021, India
}

\section{ABSTRACT}

The paper tries to unveil the truths beneath the texts of Post-Independence Odia poetry especially of the text Kaalapurusha, a long committed poem by Guruprasad Mohanty. Various poets are there in this phase those who are really serious and vigilant to the economic condition and its implications on the society and the life style of the people. It is quite clear from the national and state level investigations and various studies that literature of this period is really affected by the economic conditions. The characters of the poem or of the different novels and the stories behave and react like this because of this thing only. The common socio-economic mentality has been changed to this. The characters of the poem Kaalapurusha or any other characters are simply the representatives of the same period.

Keywords: Structural poverty, Conjunctural poverty, efficiency-cum-equity index, Vitreous humour, Paleomodernism.

\section{Introduction}

Literature and society are mingled to each other in such a way that all the components of a society are associated with the same literature and/or the literary products either in a direct way or in an indirect way. No committed literature of the world is free from the social environment. Again, economic condition is the vital most condition of the world. It is such a factor which moves all other factors in different ways.
Odisha is a naturally rich state. It is the pool of many poets' imagination since ages. Right from Sanskrit literature to so called modern Odia literature, we find the natural sceneries and wealth of the state both in the pages of poetry and as well as in prose. But, the shape of literature in various ways has been changed day-to-day as the economic condition affects. Man is now defined not by his nature and attitude but by his economic condition and status. That is because all these things are also regulated by the economic factor. One is being slave and other is being master not by their knowledge or anything but by their economic status and economic conditions. This how the society has been changed and is being regulated. This is the basic resonance of life today and this has been reflected in the so called modern literature. After independence, the real colour of the wishes of the human beings came out. Some wanted to be ruler in order to enjoy the power and luxury. They wanted to continue the British-Indian Ruler-ruled policy putting themselves in the place of British people. In this time, the financial power or the economic condition worked vital. Those who had money, they remained in the light part and the other half was the dark part which was for the poor, haven't. We can say here that they were not free financially. One kind of social independence was obtained by India but not a financial one; not an economic one. This created divide. This created discrimination and a new kind of philosophy and of course a kind of inferior psychology. 


\section{Guruprasad Mohanty: An Understanding}

Guruprasad is a cent percent active and committed poet. He is very much conscious about the economic condition of the state and thus the divides and discriminations and the psychologies and philosophies thereby. Most of the sketches of his poetry of this collection 'Samudra Snaana' throw this consciousness in all respect. Particularly in Kaalapurusha, Mohanty has given the naked sketch of the drastic economic condition of the postindependence Odisha. There is another vital thing we should notice here in this context, i.e., the women independence. If we notice clearly, we can find easily that the status of women has been declined up to the British Raj. After sudden independence and equal rights and several other factors like movements, aandolans etcetera the women of Odisha faced such a catastrophic situation. By the way, it is all about the existence and feeling of the self. Dramatically the status of women changed to this extent in the postindependence era. Where there is money, there is interest and selfishness there is pretention. Hence, we see the characters like Ramu, his wife who is also a pretentious woman, the Nurse, the School teacher, the Professor, Smarta Das, the engineer and many other people.

The burden of life is too heavy for the characters of the age. They are highly disturbed and thus living a painful life. In one hand the poor economic condition has snatched away the happiness and the liberty of life from a character and in other hand much more money and wealth has been failed to give that much pleasure and contentment to another. Life has been more and more critical and serious. At the same time it is being tasteless. That is a big problem. Man is not getting the spiritual pleasure or contentment thereby. A material life has been injected into the pure vessel of life and it has finished the joy and charm of life at the same time. Famous critic and poet Sitakant Mohapatra has rightly told in this context in the 'Introduction' to 'Bay Bath' the translated text of the master piece of Guruprasad Mohanty i.e., 'Samudra Snaana'.

"The approach to life of the poetic persona in Guruprasad is almost always unromantic and selfderogatory marked by a wit that mocks at itself. It is the voice which gives poignant expression to the weary and anguished soul of modern man. The protagonists are not heroes in the traditional sense. Nor do they lay any claim to be anti heroes. They can only be described as non-heroes, ordinary humans like us who have no complaint against either an absent God, unjust social order or other human beings. They share a common destiny. They bear the burden of life with amazing fortitude. They accept without complaint their very ordinariness and the awesome burden of living. Guruprasad believes with James Joyce that literature deals with the ordinary; the extraordinary belongs to journalism. Such acceptance is nothing short of heroic. The acceptance of the drabness of the ordinary and living without hope are indeed acts of courage." (Mohanty: 2011, 06-07)

\section{The Economic Milieu: An Investigation}

Economic condition of any society decides its living standard and social behaviors. In fact it is a quite significant indicator of the society, state or of any nation. Odisha is such a state which is naturally very rich but economically very poor. After independence of the nation Odisha faced several changes in its economy and polity at the same time. Both the factors worked very significantly and moved the common characters of the state. Especially, the people of the grass root level faced a radical change a hence a new kind of group evolved thereby. The rich became richer and the poor became poorer out of that. Under the umbrella of this condition some choose to be an opportunist group and some were somehow obliged to be their prey.

"During the colonial era, government's economic policies in India were concerned more with protecting and promoting British interests than with advancing the welfare of the Indian population. The administration's primary preoccupation was with maintaining law and order, tax collection and defense. These activities absorbed the bulk of the merge public revenues. As for development, government adopted a basically laissez-faire attitude. [...] There was some shift in attitudes especially since the 1930s signaling a more active interest in developmental problems, but this did not make any significant difference."(Kumar \& Desai, ed.: 1984, 947)

India was under development line before independence and Odisha was under that. In other words the economic and social condition of Odisha could be assessed as precarious. Professor J.M. Mohanty has narrated the literal sketch of Odisha of that time. He says- "To understand the new flowering of Oriya poetry Independence, it is necessary to have a re-look at what happened to Oriya poetry in a period 
of 15 to 20 years before Independence. Because the main trends of Oriya poetry at that time, continued to exert substantial influence on public mind even after Independence, almost till the middle of the sixth decade. Particularly two main trends may be noted, one, a romantic attitude and sensibility towards life in general, and secondly, a social and political awareness towards the contemporary life. Apparently these two were different trends, and in fact they developed differently at the time." (491) Vaidyanathan has given a clear cut view in this regard in his essay 'The Indian Economy since Independence (1947-70)'. He strictly says that the pre-independence period of Indian economy was really precarious.

"Altogether, the pre-independence period was a period of near stagnation for the Indian economy. The growth of aggregated real output during the first half of the twentieth century is estimated at less than 2 per can't a year, and per capita output by half a per cent a year or less. There was hardly any change in the structure of production or in productivity levels. The growth of modern manufacturing was probably neutralized by the displacement of traditional crafts, and in any case was too small to make a difference to the overall picture. At the time of Independence, the economy was thus overwhelmingly rural and agricultural in character. Nearly 85 per cent of the people lived in villages and derived their livelihoods from agricultural and related pursuits using traditional, low-productivity techniques." (Kumar \& Desai, ed.: 1984, 947)

The drastic economic condition forced the common and middle class and the lower middle class people to come on to the road and for the sake of their existence many of the women did prostitution and many did this under the mask of generosity. We encounter those women like Alakaa, Minati, Ramu's wife (in Kaalapurusha of Mohanty) and Pratimaa and Meeraa and some other for the sake of their existence and pleasure. Economic condition breaks the backbone of a society. This has an active impact on the life and society of the time. Odisha experienced these things vividly. A. Vidyanathan has rightly told in his essay 'The Indian Economy since Independence (1947-70)'"Immediately following the transfer of power, the government's main concern in economic policy was to control persistent and severe inflationary pressures and to alleviate shortages of essential food items which had been aggravated by the Partition. The communal disturbances and the refugee problems following Partition placed massive burdens on the country's financial and administrative resources. While these preoccupations delayed consideration of long-term development policy, the general lines of approach crystallized rapidly." (Kumar \& Desai, ed. : 1984, 949)

There was a big problem of inflation at that time to which the government targeted immediately. Again, the partition immediately after the independence and shift of administrative and political power imparted severe pressure on the socio-economic condition of the society. This condition had not only the adverse impact on the economic backbone of the nation but also the social-patterns, political scenes, and also on the literatures of different languages thereby of the entire nation. Odia literature took its seriousness about this condition not very frequently or earlier. But the way Sachhi Raoutray, Guruprasad Mohanty and some other poets took the leadership in this light is really remarkable and of course praiseworthy. B.B. Jena has tried to give a clear cut idea about the dimensions of economy of a state in his book 'Orissa People, Culture and Polity'. He says-

"Any study on the structure and components of a State's economy includes the analysis of its agriculture, irrigation, forests, industries, labour force, minerals, electricity, transport and communication, social services, housing, welfare of the backward class, rural and urban economy, problems of unemployment and planning. It is often said that Orissa is rich in resources with poor people. It has the vast coast line, dense forests, wide rivers, deep mines, large mountains, high water-falls, extensive plains and hardworking people, yet it is economically backward and politically frugal. The people are religious in temperament and tolerant by culture. Unpretentious as they are, their ways of life emanates from the philosophy of work and despair not." (Jena: 1981, 15)

Odisha was a state which depends upon its cultivation from the grain-fields. Several problems in irrigation, and other connecting things immediately dragged them down the poverty line. It was hard for them to fight for their bread and butter. Basically, the middle class people faced radical changes. Some went down the poverty line and some other preferred the industry to work and arrange their food and clothing. There came another problem. Some of the rich people started exploiting the people who shifted their occupation from agriculture to industry. Many of the 
girls and women of the conservative families preferred industry getting no way. Financial hardship became the demon for them. Post-independence Odisha is a pit of problems and the major among them is the economic problem. Some people are in such an economic state that as if they are not meant for making any wish or to see a dream. Each and every dream of there is a day dream. Even it is very hard to live and to have two times meal a day. Diseases, weather and other calamities are just like demons to them. Therefore they are coming to the footpath and even for the sake of their own life and their family they are selling their body, wills and dreams ounce by ounce. Post-independence India as well as postindependence Odisha deals with a complex socioeconomic structure. It is because of the preestimations and dreams before the independence and the immediate hopelessness thereafter the independence. Many plans have been adopted. At that time after the independence also many steps had been taken.

"Hope is yet kindled in the revivalism of economic prosperity of Orissa. The spot light on the progress of
Orissa's economy naturally throws light on its growth and perspectives projections." (Jena: 1981, 15)

By the way, after several treatments and tries we have seen some changes in the economy of India in a positive side. From there we can trace the economic condition of Odisha. But it should be made clear that the economic condition of Odisha is comparatively poor and drastic to that of the various other states. "Orissa's economic development during the two decades since the inception of planning has resulted in slow rise in the per capita income. The glaring existence of poverty, as rightly said by the Planning Commission, is incompatible with the vision of a democratic egalitarian just society. Orissa now after 23 years of planning stands as backward as before. Economic development in Orissa on all India standards puts it behind from almost all other states.'(Jena: 1981, 47) This picture could be assessed from the report of the Government from time to time. Here two tables of the post independence period may be given for reference.

Table-1

At Current Prices (Jena: 1981, 48)

\begin{tabular}{|c|c|c|c|c|c|}
\hline \multirow[t]{2}{*}{$\begin{array}{l}\text { SI. } \\
\text { No. }\end{array}$} & \multirow[t]{2}{*}{ Year } & \multicolumn{2}{|c|}{ Tesealcilatur } & \multicolumn{2}{|l|}{ State Income } \\
\hline & & $\begin{array}{l}\text { Total Income of the } \\
\text { nation } \\
\text { (in Crores Rs.) }\end{array}$ & $\begin{array}{l}\text { Per capita Income } \\
\text { of the State } 4 / 0 \\
\text { (in Rs.) }\end{array}$ & $\begin{array}{l}\text { Total income of } \\
\text { the state } \\
\text { (in Crores Rs.) }\end{array}$ & $\begin{array}{l}\text { Per capita } \\
\text { income of the } \\
\text { state (in Rs.) }\end{array}$ \\
\hline 01 & $1951-52$ & 9,970 & 274 & 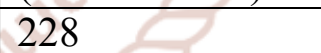 & 155 \\
\hline 02 & $1955-56$ & 9,980 & 255 & 268 & 169 \\
\hline 03 & $1960-62$ & 13,294 & 306 & 365 & 211 \\
\hline 04 & $1965-66$ & 20,621 & 426 & 633 & 325 \\
\hline 05 & $1966-67$ & 23,903 & $483 \longrightarrow$ & 769 & 386 \\
\hline 06 & $1967-68$ & 28,374 & 561 & 883 & 434 \\
\hline 07 & $1968-69$ & 28,678 & 555 & 936 & 450 \\
\hline 08 & $1969-70$ & 31,174 & 589 & 991 & 467 \\
\hline
\end{tabular}

Thus, the per capita income of the state is almost Rs. 100/- less than the national average. We can better understand the position of Orissa in comparison with other states of India in the period from 1960-61. A table may be produced out of the research. 
International Journal of Trend in Scientific Research and Development (IJTSRD) ISSN: 2456-6470

Table-2

At Constant 1960-61 Prices (Jena: 1981, 48)

\begin{tabular}{|l|l|l|l|}
\hline $\begin{array}{l}\text { Sl. } \\
\text { No. }\end{array}$ & State & $\mathbf{1 9 6 0 - 6 1}$ & $\mathbf{1 9 6 6 - 6 7}$ \\
\hline 01. & A.P. & 275 & 281 \\
\hline 02. & Assam & 254 & 271 \\
\hline 03. & Bihar & 211 & 187 \\
\hline 04. & Gujarat & 339 & 340 \\
\hline 05. & Haryana & 337 & 331 \\
\hline 06. & Kerala & 265 & 275 \\
\hline 07. & M.P. & 260 & 219 \\
\hline 08. & Maharastra & 409 & 394 \\
\hline 09. & Mysore & 238 & 266 \\
\hline 10. & Orissa & 211 & 247 \\
\hline 11. & Punjab & 374 & 407 \\
\hline 12. & Rajasthan & 237 & 247 \\
\hline 13. & Tamilnadu & 335 & 362 \\
\hline 14. & U.P & 246 & 228 \\
\hline 15. & W.B. & 321 & 329 \\
\hline \multicolumn{2}{|l|}{ All India } & 306 & 308 \\
\hline
\end{tabular}

The economic backbone of Odisha was too feeble and weak. This had its direct impact on the society and passive impact on the politics. Unemployment is the greatest problem among all. This forces indirectly to go down and kill the spirit of life to live with honesty. "The politics of instability in Orissa was discernable with the advent of the large scale politics of defection." (Jena: 1981, 286) The economic condition of Odisha is really precarious. It has a direct impact on the society and life of the people. This shapes the psychology and individual philosophy too at the same time. The nature of those women characters like Alakaa, Minati, Meera, and Pratima etcetera who represent the women of the time behave typically like this. They have adopted the method of living and prospering only for this. An economical strand decides the nature of other different strands of the society. Says Jena-

“[...] progress of Orissa's economy offers a dismal picture of its absorption of the unemployed persons, and there is the trend of bringing explosion in the entire political and social life of the state if the economy is not harnessed in right direction." (52)

The 'Executive Summary' of the Odisha state development report of the planning commission saysThe Orissa Development Report 2001 speaks about the social and economic problems of the State in details. It is of seventeen chapters focussing attention on growth of different sectors, sections and regions along with their problems and constraints. The Report particularly gives stress on poverty and poor living conditions of the people of the state.

\section{Degradation of Natural Resources and Its Consequences}

Odisha is rich in various natural resources such as: Bauxite, Manganese, Iron, Chromite, Graphite, Coal, dense forest, river, natural sceneries and tourismworthy spots, and many more things. These have yet not wisely been utilized. But the degradation and a kind of devastation of the natural resources has not only affected the economic backbone of the state adversely but also affected the environment harmfully and untowardly. The has resulted in various ways such as: drastic ups and downs in climatic condition, flooding, decreased productivity, water shortage, increased infant mortality and morbidity rate, etc.

\section{Infrastructure Development}

It is quite clear that the economic development of a state definitely depends upon its blooming status of the social and economic infrastructure. From this point of view it could be said with the voice of the planning commission report that,- "when the development status of the key infrastructures in Orissa is compared with the average development status of such infrastructures in the country by the formation of composite development index, the development position of Orissa as such does not reveal its actual backward status in comparison to many other States in India. However, when the development indicators of a few key infrastructures are analysed and compared with many other major States and also with the allIndia figures, the deficiencies and weaknesses of such infrastructures in Orissa are clearly revealed to manifest its backward status. Added to this, it is further found that the level of disparities in the development status of infrastructure among the present 30 districts of Orissa is fairly high. Also, its access across space and people is highly unequal. It is observed from the observation made during the time of field study that mere existence of infrastructure does not ensure its service utility for the poor and downtrodden. The maintenance and supervision of many key social and economic infrastructures particularly in the backward highland districts of the State is observed to be very poor. As a result, such provisions have failed to generate the intended 
development effects among the poorer and vulnerable sections of population."(pp.- ii/ brief summary of the report of the PC). Now-a-days some developments have been taken place in the village sectors.

\section{Structural Changes of the Trend of Economic Growth}

The long term growth of NSDP (over the period 1950-51 to $1988-89$, at $1970-71$ prices) has been 2.7 per cent which is not really a good growth or satisfactory in any respect. In between 1970-71 or 1980-81 prices, the economy has posted the highest growth rate historically during the decade of the 1980s. Says the Planning Commission report, "At 1980-81 prices, the growth rate of NSDP has come down from about 4.8 per cent to 3.8 per cent, which is also the case for all individual economic sectors, with the exception of mining and quarrying (from $8.7 \%$ to $12.7 \%)$, unregistered manufacturing ( $2.6 \%$ to $8.1 \%)$, communications $(7.9 \%$ to $13.7 \%)$ and trade, hotels and restaurants (from $5.7 \%$ to $6.8 \%$ ). In particular, it is to be noted that the agriculture and animal husbandry sector has seen a fairly sharp decline in the growth rate in the 1990 s - down to 1.9 per cent from 3.1 per cent in the 1980s." From the above information we can draw the economical status of the State of the mentioned period.

\section{Workforce Characteristics: At a Glance}

The available data clearly suggest that there has occurred a decline in employment rates for both males and females and in both rural and urban areas. Even this trend of unemployment has been continued till now. But more particularly it has been seen in between the period from 1983-84 to $1999-2000$. It is because the labour force participation rate has not satisfactorily increased much between 1987-88 and 1993-94 and at the same time there has been a squeeze on employment during the period. As per the data and report we see employment only in a very few cases. In fact, the status of employment was seen only in a few pertinent fields and they were the casual labour category and the other was regular wage employment. Here the rate of self-employment is very less and negligible in fact. The regular wage employment of males was much greater than that of the females. The degree of casualisation has significantly been increased in the case of rural female workers just before the 1990s. The report speaks clearly that- "The rate of open unemployment is the highest in Orissa among the low-income States. The degree of visible underemployment is again higher in Orissa than for other low-income States and all-India, and this is observed both for male and female workers and also in both rural and urban areas." And this was the problem and precarious situation of our state of that time. It was a kind of misery only. It is very clear that this would have a clear cut impact on the social life of the society. Literature has just reflected the same and somewhere it has reflected and/or refracted the reflection. But in this matter we can clearly get a sketch of Guruprasad's commitment. He is really a serious and committed poet of Post-Independence Odisha. The lymph and corpuscles of his poetry especially of Kaalapurusha, the famous long poem, keep the socio-economical matters of the time.

\section{Industrialization in Orissa: Pattern, Policy and Prospects}

The different aspects of the industrial economy of Orissa, particularly of that period, in an inter-regional framework are really significant to various other implications. For example, what we encounter in the literatures of the same period, or what we see in various socio-cultural and political and other fields etcetera. From the analysis, it is observed clearly that Orissa's industrial structure has hardly shown any improvement as compared to other States. In most of the cases, the presence of highly capital intensive industries with cost disadvantages in fuel, interest payment and depreciation has resulted in heavy losses. As a result, the prevalence of low wages in many industries causes low productivity of labour. And again, because of poor agricultural base, the emergence of an active local entrepreneurial class has been stifled. Therefore, in this regard the report of the commission says, "The persistently disadvantageous position of the State raises basic questions of neglect and misdirected policies of the Centre as well as the State." However, it has also been seen that many of the contractors, many of the rich people have exploited the middle class and lower middle class people in this flow. Many women and girls became the prey of these kinds of people in this way. A number of poems, stories and novels have been there in the post-independence era in Odia literature and also in literatures of various other Indian languages like Bengali, Marathi, Gujarati, Malayalam, Hindi, Konkani, Sindhi, Telugu and Tamil. Lack of proper infrastructure, especially, transport and power, has severely impaired both growth and diversification of industries in the State in this post-independence era 
which had led us to a malignant economic state or in other words we can say that it has led us to economic instability and insecurity.

\section{Poverty and Living Conditions: A Bird's Eye View}

Orissa is one of the poorest States of India. Compared to coastal belt, poverty is more in northern and southern belts of the State. It is higher among the scheduled tribes (ST) as compared to scheduled castes (SC) and general castes. Furthermore, the percentage of rural families living BPL is found to be much higher in the State. Besides structural poverty, Odisha also faces several other types of poverty like conjunctural poverty (due to floods, cyclones, droughts, etc.) and destitute poverty (of persons lacking either money or material to survive). In terms of the several development indicators like literacy rate, infant mortality rate, per capita income, etc, the living conditions of the people of Odisha are considerably lower than the national average. It is also true that larger inter-district variations are found in the living conditions of the people of the state. The performances of the welfare activities like EAS, PDS, ICDS and MDM are also found to be very poor according to the planning commission report.

\section{Development Scenario of the Villages of Odisha}

India is a developing country and Odisha is one of the poorest states of it. Therefore in a poor and backward (from different viewpoints it is said backward but the most significant of them is economic viewpoint) state like Odisha it is least expected that the development lay out of the village and the outline of the pace of socio-economic transformations could be better. Various non-governmental and also governmental socio-economic survey of different types of villages in different regions of Odisha incontrovertibly reveals that the state has to make a longitudinal perspective stratagem for the transformation of the subsistence oriented backward agricultural economy in order to solve the problem of poverty and to improve the 'quality of life' of rural people.

\section{Concluding Remarks Regarding the Economic Scenario}

While the economic indicators of development are very poor, which produce acute poverty conditions, there are a number of social conditions of deprivation that tend to perpetuate poverty. These in turn hold back the backbone of social development. This is a kind of vicious circle. With reference to this the government is also focusing to increase the pace of growth and improve the economic and social well being of the poor. Again, another most important thing is Sectoral poverty reduction. And it can be considered as the responsiveness of poverty reduction to growth. This is derivable from the implicit elasticity of poverty with respect to growth of the entire state i.e. by what per cent the poverty ratio declines with one per cent increase in growth. Therefore, here we may take a normative approach and assign equal weights to the afore mentioned two sectoral parameters as the basis of sectoral allocation of total plan outlay. Thus the two parameters can be added up and called efficiency-cum-equity index.

On the basis of the report of the planning commission or on the basis of this efficiency-cum-equity-index a growth rate of 6.2 per cent per annum during the Tenth Plan along with a poverty reduction of 7 per cent has been proposed in the Vision Statement. From this something from the economic condition can easily be assessed.

\section{State Domestic Product}

The SDP of Odisha at that time was only $2.80 \%$. But it increased to $3.01 \%$ after ten years, i.e., during 197071. This level continued for another decade. But it came down suddenly during $1990-91$ to $2.75 \%$ and further thereafter too precariously. The trend is reflected graphically below. 
Table/ Figure No.-3

\section{Sha re of SDP at Current Price (\%) Odisha}

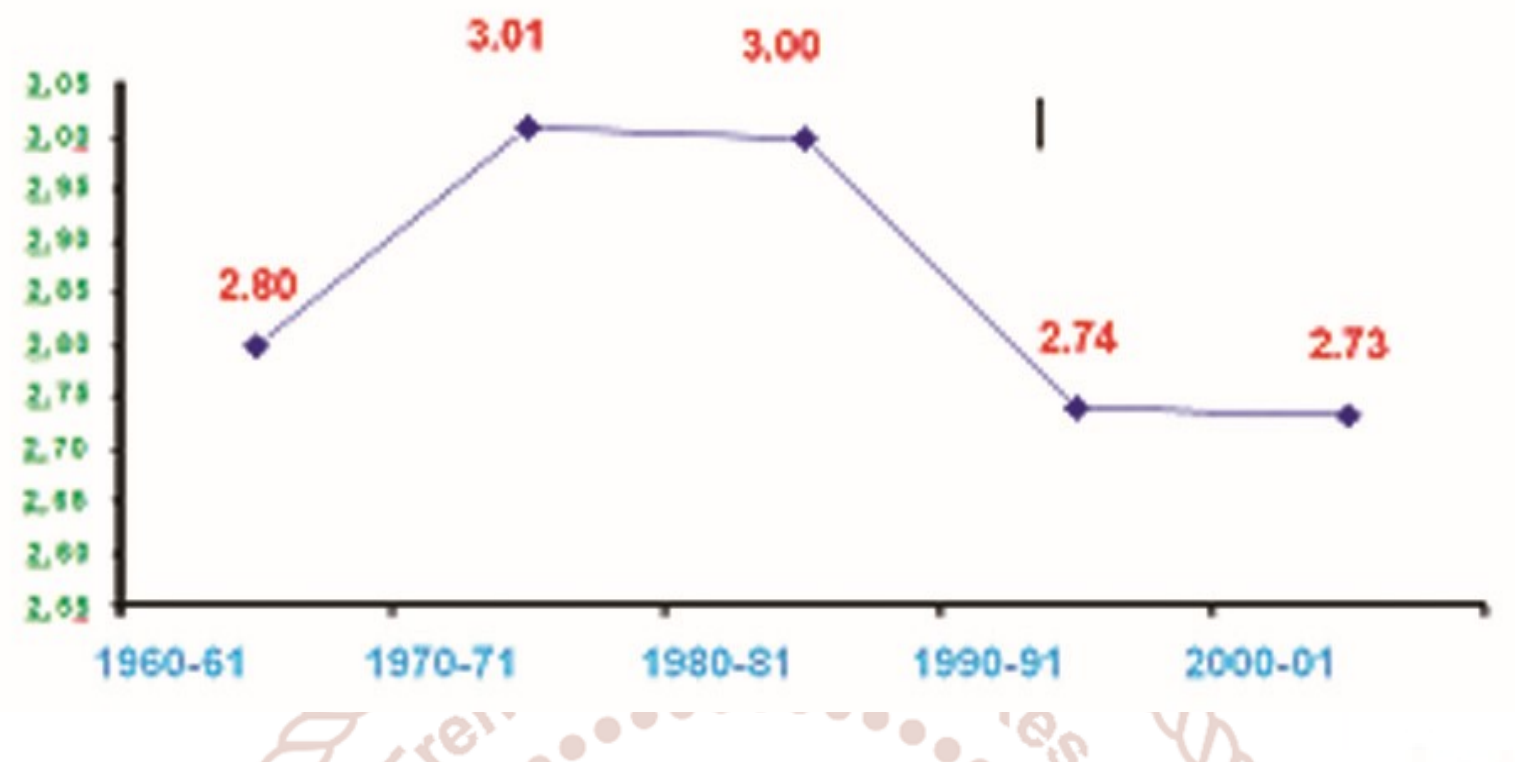

GSDP is widely accepted by the economists in order to measure the economic development through the entire country. In last 40 years it has been used in India for measuring the economic sustainment for its limitation in concept and methodology. By the way, the exact and uniform status of the people could not be accessed from this because it depends upon the per capita income (PCI) concept. This concept is not at all prompt in order to find the exact condition of each and every citizen of a sate or nation. Though it is deceptive and delusive or a distorted one method still it is used to find the status of India since independence. The economic condition in this light could be well accessed from 1960-61 to 2000-01. Some states had PCI above the national average and some other have below that NIA. We can well find that in 1960-61 reading Karnataka had the highest PCI all over the nation followed by Maharashtra and West Bengal (WB). Five states of India, in this particular phase (1960-61) had PIC above the NIA. They are Karnataka, Maharastra, West Bengal, Gujarat and Punjab. Punjab topped the list in 1970-71 from the above given list with five states above the National
Average PCI. Karnataka had some poor performance here and it came below the NA. Punjab, Maharastra, Haryana and Gujarat remain intact, i.e., above the NA in 1980-81.WB came near the NA. Similarly, in 199091, the high income states were Punjab, Maharastra, Haryana and Gujarat. The middle income states were AP, WB, Tamil Nadu, Kerala and Karnataka in the period. The PCI of these states were very closer to that of the NA. There was only with an $18.8 \%$ share of population and the SDP was only $29.95 \%$ of these four states particularly. The report says that the population share was only $31.68 \%$ where the SDP share was taking the average of 1988-89, 1989-90 and 1990-91 at 32.95\%. Though seven states (Punjab, Maharastra, Haryana, Gujarat, Tamil Nadu, Kerala and Karnataka) of India had crossed the NA and had occupied a good place of higher income states still surprisingly five other states (Odisha, Bihar, MP, UP \& Rajasthan) were still continuing under the category of lower income states during the last forty-fifty years from 1950-60 to 2000. This is evident from the table below and the graphs attached herewith. We can see how $45 \%$ of population yields only $28.89 \%$ of SDP. This clearly shows the picture of Odisha. 
International Journal of Trend in Scientific Research and Development (IJTSRD) ISSN: 2456-6470

Table No. 4

PER CAPITA STATE DPMESTIC PRODUCE OF MAJOR STATES IN CURRENT PRICE

\begin{tabular}{|c|c|c|c|c|c|c|c|c|c|c|c|}
\hline State & $\begin{array}{c}1960- \\
61\end{array}$ & $\begin{array}{c}1970- \\
71\end{array}$ & $\begin{array}{c}1980- \\
81\end{array}$ & $\begin{array}{c}1990- \\
91\end{array}$ & $\begin{array}{c}1995- \\
96\end{array}$ & $\begin{array}{c}\text { 1996- } \\
97\end{array}$ & $\begin{array}{c}1997- \\
98\end{array}$ & $\begin{array}{c}\text { 1998- } \\
99\end{array}$ & $\begin{array}{c}1999- \\
00\end{array}$ & $\begin{array}{c}2000- \\
01\end{array}$ & Time \\
\hline Andhra Pradesh & 275 & 585 & 1358 & 4728 & 8615 & 11224 & 11683 & 13993 & 14878 & 16373 & 59.50 \\
\hline Bihar & 215 & 402 & 943 & 2665 & 4094 & 1014 & 4474 & 4813 & 5108 & 5466 & 25.4 \\
\hline Gujarat & 362 & 829 & 1967 & 5913 & 11036 & 16153 & 16536 & 18815 & 18685 & 19228 & 53.0 \\
\hline Hariyana & 327 & 871 & 2351 & 7508 & 13770 & 16707 & 17749 & 19716 & 21551 & 23742 & 72.0 \\
\hline Karnataka & 485 & 641 & 1454 & 4598 & 9004 & 11670 & 12566 & 15420 & 16654 & 18041 & 37.2 \\
\hline Kerala & 259 & 594 & 1385 & 4200 & 8324 & 13050 & 14231 & 16029 & 17709 & 19463 & 75.1 \\
\hline Madhya Pradesh & 252 & 484 & 1181 & 4049 & 6518 & 8819 & 9455 & 10682 & 11626 & 10803 & 43.0 \\
\hline Maharashtra & 409 & 783 & 2244 & 7444 & 15244 & 17619 & 18954 & 20356 & 22604 & 23726 & 58.0 \\
\hline Orissa & 217 & & 1173 & 3077 & 6079 & 6401 & 7831 & 8324 & 8733 & 8547 & 39.4 \\
\hline Punjab & 366 & 1070 & 2620 & 8318 & 15504 & 17353 & 18762 & 21184 & 23254 & 25048 & 68.4 \\
\hline Rajasthan & 284 & 651 & 1220 & 4191 & 6958 & 10102 & 10997 & 12348 & 13046 & 11986 & 42.2 \\
\hline Tamil Nadu & 334 & 581 & 1324 & 4978 & 9668 & 13327 & 15404 & 17613 & 18623 & 19889 & 59.5 \\
\hline Uttar Pradesh & 252 & 486 & 1272 & 3590 & 5963 & 7501 & 7779 & 8633 & 9323 & 9721 & 38.6 \\
\hline West Bengal & 390 & 722 & 1643 & 4673 & 7851 & 19857 & 11682 & 13641 & 14894 & 16072 & 41.2 \\
\hline All India & 350 & 720 & 1741 & 5365 & 10149 & 11964 & 12707 & 14396 & 15626 & 16707 & 47.7 \\
\hline
\end{tabular}

Table/Figure No-5

PER CAPITASTATE DOMESTIC PRODUCT OF MANOR 14 STATES

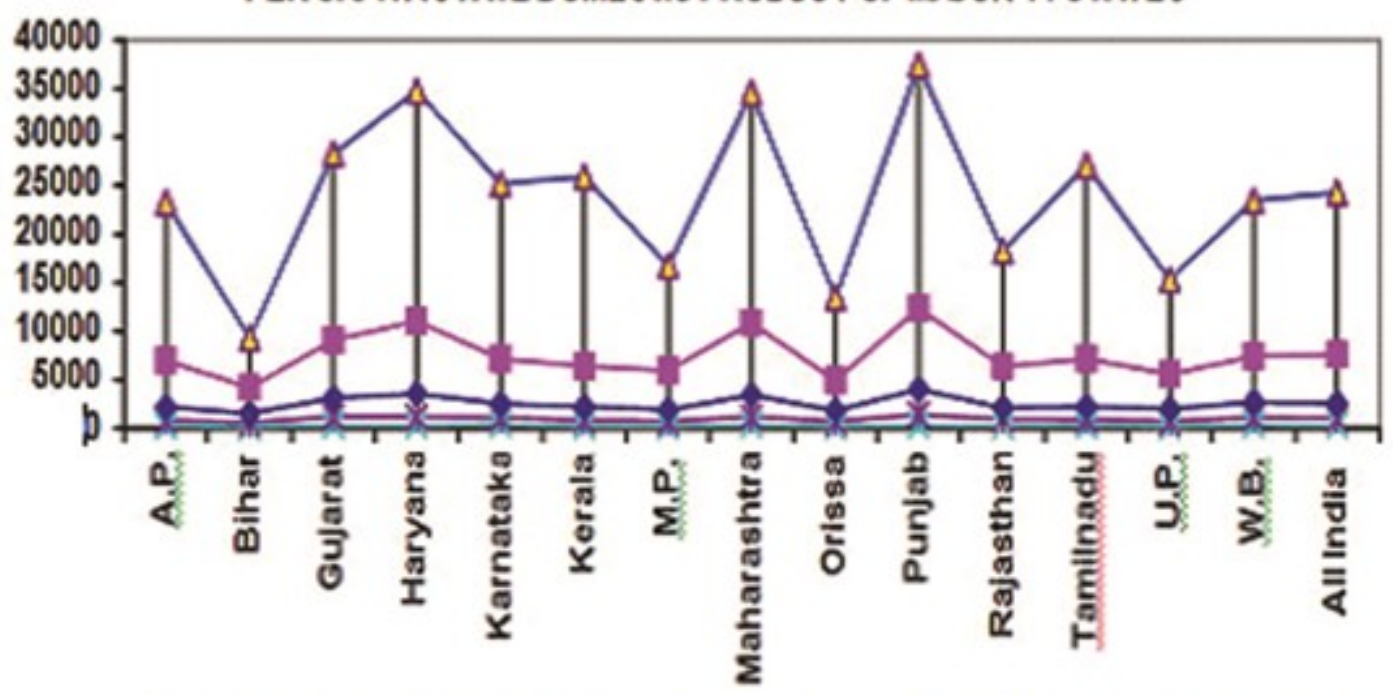

$1960.61-1970.71$ 
Figure No.-6

\section{PER CAPITA STATE DOMESTIC PRODUCT OF 14 MANOR STATES}
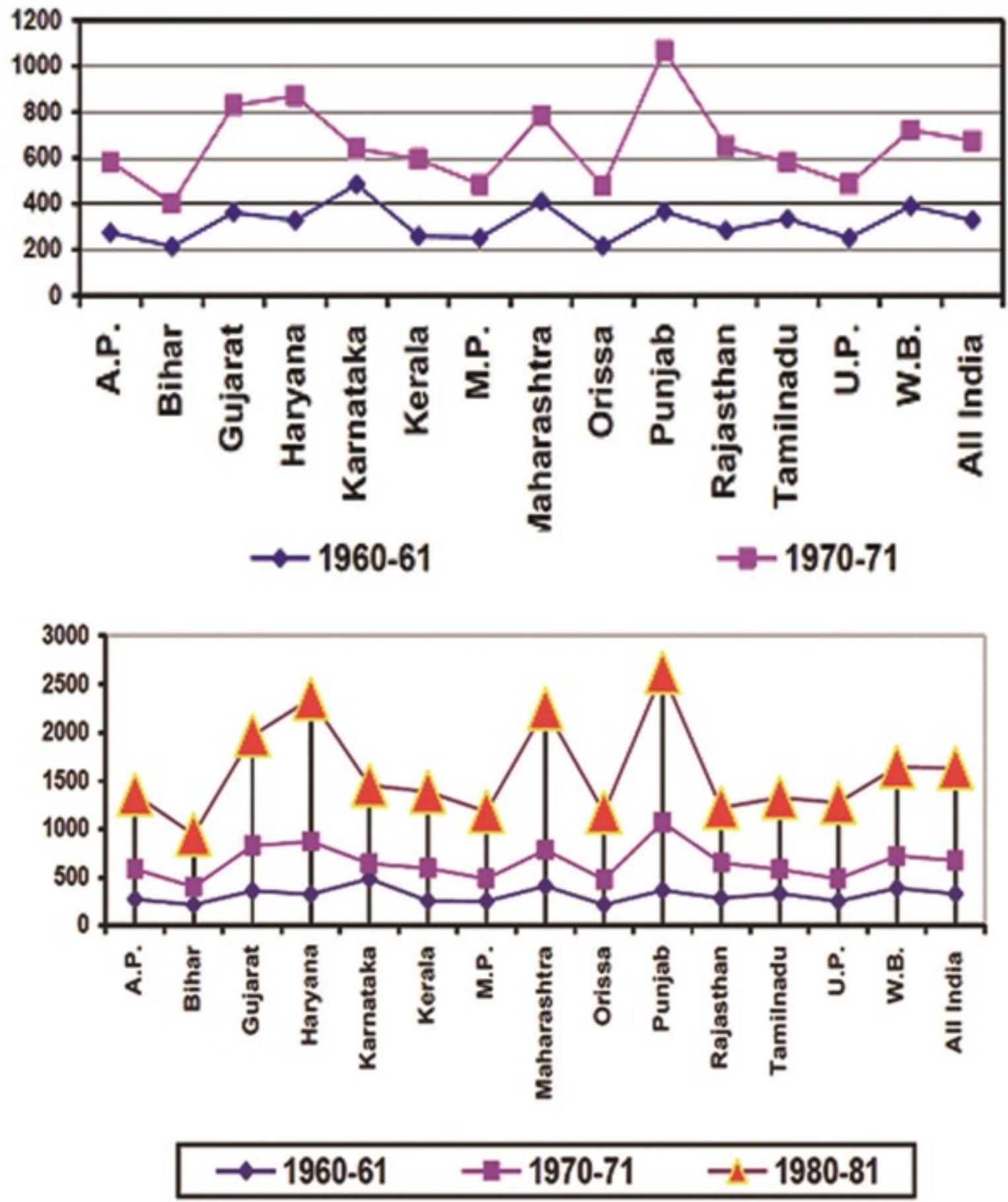

Figure No-7

Post-Independence Odia Literature from the Economic Spectacles: At a Glance

The post-independence Odia literature is quite closer to the realities. These realities are some time social and some other time these are economical and political etcetera. On the basis of these realities we encounter a new kind of poetry. We call this new poetry. Guruprasad has rightly named this 'Nutana
Kabitaa'. He wrote an anthology of poems named in this title with his fellow friend Bhanuji Rao. Really, these poems are not only new in taste but also they are too much different from the earlier poetry and the poetic trends. In style, in theme, in commitment and in breathing also these poems were too much different and special. Sachhidananda Routray and Guruprasad have played significant role in this regard. We can 
also take the few names of the Odia poets, such as Benudhar Rout, Binod Chandra Nayak, Sitakant Mohapatra and Ramakant Rath etcetera. But among these two generations we see some beautiful specialties of Mohanty. He is very much conscious about the economic conditions of the contemporary society. Hence, his inferences are directly found in his poetry. Kaalapurusha, Gobara Ganesh, Harekrushna Das, Picnic, Chhutira Kharaa, Priya Bandhabee, Nihita Godhooli etcetera are the poems with these pigments and also of this kind of taste. His sonnets are very powerful speakers and painters of the contemporary socio-economic sketch or scenario. Professor J.M. Mohanty has rightly depicted the sketch of the socio-literal environment of that time. He says-

"The post-independence Oriya literature was the product of change in time, a change in response and sensibility that resulted in change of attitude and understanding. It was an outward moment, a moment away from the local concerns to larger contexts, both Indian and larger than Indian, and was perceived and achieved in a number of dimensions." (437)

Jatindra Mohan Mohanty has indicated four writers in this regard who have laid the foundation of modern and post-independence Odia literature. They are Gopinath Mohanty, Surendra Mohanty, Sachhi Routray, and Manoranjan Das. All these four writers are veteran in their respective fields but it can never be neglected that Guruprasad Mohanty has written a few poems but what he has done for the new trend setting after the Post-independence era is really remarkable and unforgettable. He further says"Apart from the 'Founders' we have noted, there were other writers too, who provided a link between the pre-Independence and post-Independence days. The more important among them were Godabarish Mohapatra poet, Ananta Patnaik poet, Nityananda Mohapatra novelist, Laxmidhar Nayak novelist, Gopal Chhotray (1916-2002) dramatist Ramachandra Mishra (1921-1992) dramatist, and Bhanja Kishor Pattanaik (1922-2001) dramatist. They all had earlier beginnings, yet it was only after Independence that they achieved success and popularity and were accepted as major figures who contributed substantially to the growth of new literature." (465)

\section{Guruprasad's Kaalapurusha through the Prism of Economics}

Guruprasad is really a vigilant poet. He is conscious about the economic condition, political scenarios and various other factors which mould and affect the human behaviour. Guruprasad has written many poems in this regard. In his Harekrushna Das, we can see this kind of narration and the clear cut reason beneath it. He clearly says there that this time is pregnant with both fear and sin. This is the reason which has been concentrated as his anti-romantic philosophy and further a concept of death and depression. Life is not in the selection of modern man. Rather death is very amusing and beautiful for them. But the Indian culture has that much of power to resist the suicidal tendency to come into our social thought. In his 'Pramukha Kabi Katipaya' book says Satapathy, "The fragments of life are here all over in this city where there is only the lifeless body and wills." (Satapathy: 1985, 138) The European poetry of the Post-World War-I \& II were the ideal of almost all the poetry of the rest of the world and especially of the northern hemisphere. After fifties, many poets realized this truth in their own soil and air. Guruprasad has realized and felt this type of thing in the air, water and soil of Odisha. Soon after the independence, we have started to live in a pseudosocial earth.

We can see the reflections of a collective economic condition and also the condition of the protagonist. Though it is very much symbolic still an economical force always decides the motion of psychology and thought process of the character, protagonist or the author himself. A few instances can be given from the translated work (Bay Bath) of 'Samudrasnaana'. The narrations like- "The heat of Baisakh and Jyestha / simmers under the sky's tin roof,/ when everything fainted / everything seemed unexciting / no energy in the bones/ in the nerves and veins,/ there was no conflict in hope/ annoyance or passion,/ sometimes houses were on fire,/ in the pulled-in stomach/ under the drops of saliva/ of the dog's tongue,/ whatever there was/ was a dying life/ everything was right,/ in order." (2011:115) or the expression "When the light in the / invalid's room dims and the noise on the football field/ dies down,/ touching the roots/ and hollows of the leafless tree/ the restless spirit/ of the darkness/ looks for someone,/ then, Bose babu, the city's trader/ drives away in his car/ leaving behind/ our one-storied building./ I keep gazing/through the window/ I see no flowers on the braid nor a brassiere 
on the bosom/ my father was away in the court/ mother went to ask for a loan/ and my brother was in the hospital,/ the Raja festival was only three days away."(2011:132) or, “[...] O Akrura, O Uddhaba/ my friend and my life's companion/ stand a while/ I also carry a load on my back, like you,/ when today/ the kingdom and the kings are no more/ and the subjects and minions are shattered / I follow you,/ where is the end/ and the beginning of the road ?" (2011:133) could be cited herewith in this favour. All these events yield very painful consequences to which we say the miseries of modern life. Especially, the modern man is an epitome of pain and suffering embedded in spiritual alienation. "The Post-War literature preaches and exhibits the victory of science and technology, the processions of feudalistic attitude, the suffering and cry of the middle class and lower middle-class people, and the poisonous sting of the declined man. With these things the poems or the literature of this time has given a mixed taste."(Pujari: $1971,128)$ It is quite hard to find the inner sketch of a poet's mind. For the above reasons it is quite harder to find an impersonality in the matrix of modern poetry. L.G. Salinger has rightly told, "a poet's mind should remain 'inert' and 'neutral' towards his subject matter, keeping a gulf between the man who suffers and the mind which creates"(1971: 128-29) in this regard in order to map the poet's mind. The drastic economic condition of man is not at all worth to welcome. Hence, the poetry is quite fond of using wits as its own asset. It is as satiric as urban in another word. Vast consciousness and vast things are associated here. Says Pujari, "Though late, the tone changed in Odia literature due to a great economic scarcity and down-fall. [...] some people like Gopi $\mathrm{Babu}$, ndra Babu, Kalindi Babu took chance in this situation and wrote literature of those kind of taste."(106) Guruprasad, Sachhidananda Routray, Bhaniji Rao, Chintamani Behera, Saubhagya Mishra, Sitakant Mohaptra and Ramakant Rath etcetera wrote poetry in this tone. Here, the poetry Kaalapurusha has been unveiled. It has been dissected by the knife, scissors and blades of economics. Hence, the truths beneath the texts of Post-Independence Odia poetry especially of the text Kaalapurusha, a long committed poem by Guruprasad Mohanty have been revealed herewith. Various poets are there in this phase those who are really serious and vigilant to the economic condition and its implications on the society and the life style of the people and on the basis of the above things they have tried to sketch the inner minds of the people and the society by their characters. It is quite evident from the national and state level investigations and various studies that literature of this period is really affected by the economic conditions. The characters of this poem (Kaalapurusha) or of the different novels and the stories behave and react like this because of this phenomenon only. The common socio-economic mentality has been changed to this extent and it implies their behaviour to which we encounter in the poem like Kaalapurusha. The characters of the poem Kaalapurusha or any other characters are simply the representatives of the same period. The mental dilemma and the states of mind of the characters are the noticeable things of the poetry. A number of poems of Saubhagya Kumar Mishra, Sachhidananda Routray, Ramakant Rath, Sitakant Mohapatra and few other poets could be well examined and accessed in this regard. Saubhagya Mishra's 'Sukadev Jena' poem is of this kind too. The actions and reactions of any character of a society or any poem, in other words, are dependent upon the socio-cultural as well as the socio-economic conditions and environment. Ramakant Rath's 'Chandramaa Ra Chudi' (The Bangles of Chandrama) is a fine poem in this regard. What Chandra Beheraani does in the midst of her drastic destitute economic condition is only and only for the sake of her existence. The existential philosophy is thus the central theme of the literature of this time. In Guruprasad's poetry we also see the naked truth of the time with more vigilant eyes. The precarious scene could be noticed in Guruprasad's Kaalapurusha right here.

"Smearing the/ City's face with ashes and charcoal dust / The night's fog walks the lanes/ And bylanes, groping for its way / When the effect of night's opium / Takes hold/ When folding its wings/ The sky descends, / I thought, so many people / So much flesh, so testy/ The gathering of so many / Hands and feet,/ Black and white, big and small,/ Where did they come from,/ from the pages of history,/ or from someone's whim/ searching for water from the stream/this swarm of strange locusts/ without past or a future/ without ancestry./ Filled by the dust of road the chest breathes heavily/ On the brick and lime paved floor / The gaze straps at the post office./ Riding the rickshaw and horse-cart/ When the throat dries/ When the souls roam the riverbank/ This evening,/ Are these true or false/ now, today or tomorrow ?" (2011: 11819) 
The drastic economic condition of that girl has made her obliged to be engaged in unhealthy practices. She was engaged in sex-work which is unethical and unsocial at the same time. She is the slave of conditions, the hard time. Professor Dasarathi Das has rightly told, "Odia poetry is a victory-march of blood, imagination and intellect." (314) Guruprasad has given the naked sketch of the event which is really heart touching and the narration has its ability to snatch some pure drops of tear from a true heart of human being. The lines could be felt with intense care- "Like a snake in the forest/ I remain motionless and still/ I endure a million toutures/ of body, mind and the soul./ on, my body/ the stench of Puspabati, the harlot/ the love cries of/ Chandrabhanu and Labanyabati,/ The smell of beef, of wine and women / on my body,/ all the world's / nomadic light and darkness./ leaning my back and darkness." (2011: 132-33) The consequence is very precarious and painful. This could be noticed from the lines below:

"Leaning my back against the wall of the prison, pressing the kerchief to the eyes I cried, at the loss of parents, friends, years, clean, countrymen, of life, property and wealth of righteousness, cattle and Brahmins. I cried, sensing the sound of time passing, old age, death and disease and also the fear of the assassin." (2011: 133)

Literature is surely the criticism of life and in the Post War literature or in the Post-independence literature it is very transparent that poetry has something more to do, it something beyond the literary limits. Hence, it has taken the incarnation of revolution, a preacher of philosophy and a powerful means of transmitting the real idea of life. Poet is a better philosopher here. Here we can remember the arguments Eliot, Welleck and F.R. Leavis. Professor Basudev Sahu says in his book 'Aadhunika Saahitya Bhashya'- "A great poet is bound to be introspective and should have inward speculation rather than being outward. With this he can change the individual mind as well as the collective mind of the society and he can fetch a revolutionary change in the society."(94) Further, he has told that "gradually the social and individual both the lives are being more and more complicated day by day. The human mind is whirling sometimes in deep sorrow and sufferings and some other time in fake feudal attitude." (94) The post-independence poetry is running in the passage of life and death, essence and existence, and overall under the umbrella of mental sufferings. Says professor Prasanna Kumar Swain in his book Saahityara Deepti o Byaapti-

"The sense of alienation has been started from the third and forth decade of twentieth century in the life of Indian society. This time is pregnant with fear and sin. Man has been helpless and thus he has left the village and started for the city-life. He has been cityoriented. The village people of Odisha have started moving towards the Tea-garden of Assam, Kaalimaati of Kolkata, cloth mills of Gujarat to be in city and to live. But they have been turned into Daily wagers, Majdurs, labourers, Gadams and Bethi even for the entire lifetime under the cruel clutches of situation. Thus the life of these people has been so drastic and painful that it can't be expressed in terms of language. They have spent their lives like cheap and unwanted animals. It was so precarious and deplorable. The dream of pre-independence ear has got a strong shock after the independence." (163-64)

During the post-independence era it has been a great question before the man of twentieth century is how to live or survive. The rhyme of poetry has been the rhyme of life today. Hence, poetry has been made more practical and more realistic. Professor Kunja Behari Das says- "the main source of modern poetry is Europe. Due to several struggle, revolution, war, industrial revolution, scientific inventions, analysis of different philosophical thoughts the seed of modern European thoughts have been germinated; a kind of revolution has started in the field of art, sculpture and architecture as well as in the field of literature. In modern Indian literature we encounter this." (384) A revolutionary change has been witnessed in the post 1960s poetry and also in the different forms of literature. "Specially, the age is special for its attempts for a co-ordination of its prose and poetry. It is because the range of prose and poetry has been squeezed radically. In one hand the prose has been poetized and in other hand the poetry has been prosaic in nature," (114) says Pujari. We see that both the disciplines are focusing on the problems and miseries of human life. We see same sketches of human being and his destitute in both the fields. Literature is such an art which is devoted for the life sake. Here, in the post-independence poetry and of course in other forms we encounter the drastic sketches of life which has been badly affected and devastated by the economy. "A single theme, as a result has been expressed in two tunes."(114) He further adds, "In between the last decade various horizons of Odia 
poetry have been inaugurated. As a result, in the configuration of poetry or in the technique of poetry and in presenting the context and the angle of vision several new turns have been encountered. The big thing ever occurred here is that a rigorous quest and serious attempts have been encountered in the poetry." (115) We usually meet the metaphysical poets as well as the poets like Baudelaire and Eliot. But the main thing ever we see here is wit, irony, and mimic, satiate to the life. Urbanity has devastated the purity and sanctity of our culture, tradition and even of our entire charm and spirit of life. Guruprasad's poetry and especially the Gobara Ganesha and Kaalapurusha are made for this purpose only. As Wilson has told that the contemporary poet is dealing with either one thing of the following. One is serious aesthetics which is associated with static, serious and paramount beauty and the other is the beauty of his own day-to-day life. Therefore "his spectacles are not totally satiric or sarcastic, rather it is a mixed product of Wit and Passion which is constitute of materialism at one hand and spirituality at other hand,"(116) says Pujari. The greatest poet of twentieth century Mr. Eliot says in this regard that it is the unification or association sensibility of the poet in his/her poetry. Therefore in an attempt to define the metaphysics in poetry T.S. Eliot said that it is a direct sensuous appreciation of thought or a creation of thought into feeling. Professor Bidhubhushan Das has righty told in this regard that "today, in the midst of the twentieth century it hard enough for us to know for the outstanding expansion of the materialistic world and wants. Many may not accept it as the age of decline and suspense but it is very much true that the value and form- both the things of literature have widely been changed and mutated." (Pragnyaa Saahitya, Pg. 02) The literature has already undergone the process of mutation and metamorphosis. And this process started vibrantly right from the post-independence phase.

The economic status of people of that time made the life and society of that type. Hence, literature also told that thing and had deals in various ways with that. Some poets noticed this and took this much more seriously. They went against the conditioned reflex of the literary trend. Guruprasad and Routray are the main voices out of them. Guruprasad's Samudra Snaana and especially the long poem Kaalapurusha has significant and sui generic contribution towards that. In this phase, the new poetry came with new commitments with new dictions, vocabularies and form and features. As a result the form and nature of new poetry has been more sustained in quality. Umacharan Pujari has rightly told in this regard with a close dissection of the matter that-

"Overall, a delicate experience and condensed and free feeling inside the matrix of the form of poetry have been expressed. Aesthetics, sensibility and the cubism of reality are the three dimensions of modern literature." (124)

India became free from the colonial clutches in 1947 but the post-independence period was not at all free from the economic problems. It was not a freedom but independence. It is very interesting to note that in the pre-independence era the theme and the effect of the call for the abolition and rejections of foreign materials was so impactful but the reverse thing was seen in case of literature. The poets and the story tellers, even writers of other forms were importing the foreign themes, techniques and substances. There was a kind of enthusiasm in literature for bringing the foreign substances into the Indian literature. Professor Dasarathi Das says- "Odia literature is not an exception in this practice." (289) The postindependence economic status of the nation has poured its serious impact into the blood vessels of the literature of this time. We see modernism in two forms: Paleo-modernism and Neo-modernism. This term modernism is not at all a disable one. It is the most functional and diffusing term. Dasarathi Das has told, "Neo-modernism is absent in modern Odia poetry even in the post-independence phase". (296) this could be seen from the nomenclatures of the modern poetry in this period. Sitakant, Ramakant, Kamalakant, Saubhagya, Benudhar, Sachhidanand, Pratibha Satapathy, Sarat Chandra Pradhan, Chintamani and of course Guruprasad- all these have some weakness towards the past, ancient culture, tradition and other related things. They have just made an experiment with the elements. Pure modernism is rare in Odia literature and of course in Guruprasad Mohanty's poetry. The few names of the books may be seen in this light. They are: Samudra Snaana, Chitranadee, Shreeradhaa, Shreepalaataka, Saptamarutu, Shabaree, Bajra Jaana, Manikarnikaa, Jajaati, Ruuk, Srotara Naama Ruta, Pingalaara Soorjya, Trutiya Chaksyu, Mantrapaatha and many other things. Now poetry has come down to the floor of experience from the platform of meaning and intellect. It has taken its soul very importantly. Human 
soul and the soul of poetry are now walking together on the pavement of reality.

\section{Conclusion}

We can briefly conclude here that the economic condition has its active impact on literature and the society and it has equally been reflected in Odia literature even in the poetry of the Post-independence phase in many of the poets' works in various ways. The PIOP is really too much committed to the society, its socio-economic status and impacts and inferences too. In Mohanty's Kaalapurusha we also see the same tune and its echo. We can tell the economic condition of Odisha as the vitreous humour of the PIOP. Many of the scenes and sub context of the poem have been infected and affected by the economic condition of Odisha at the verge of Independence.

\section{Work Cited:}

1. Das, Dasarathi, Saahitya Bibeka. Cuttack: Agraduta, 1996.

2. Das, Kunja Behari, Saahitya o Samaalochanaa. Cuttack: Orissa Book Store, 1980.

3. Jena, B.B., Orissa People, Culture and Polity. New Delhi: Kalyani Publishers, 1981.

4. Kumar, Dharam \& Desai, Meghnad, ed. The Cambridge Economic History of India. Cambridge University Press, 1984.

5. Mohanty, Guruprasad, Bay Bath (Samudrasnaana). Trans. Sangram Jena and Aurobindo Behera, Bhubaneswar: Pakshighar Prakashanee, 2011.

6. Mohanty, J.M., History of Oriya Literature. Bhubaneswar: Vidya, 2006.

7. Pujari, Uma Charan, Odia Saahityare Paaschaatya Prabhaba. Bhubaneswar: Gita Prakaashanee, 1971.

8. Sahu, Basudev, Aadhunika Saahitya Bhaashya. Puri: Shaswati Saumya Sahu, 1984.

9. Satapathy, Nityananda, Pramukha Kabi Katipaya. Cuttack: Nalanda, 1985.

10. Swain, Prasanna Kumar, Saahityara Deepti o Byaapti. Cuttack: Orissa Book Store, 1996 